\title{
Transcultural approach to the health-related quality of life of cancer patients
}

\author{
Abordagem transcultural da qualidade de vida relacionada à saúde de pacientes com câncer
}

Namie Okino Sawada ${ }^{1}$, Bianca Sakamoto Ribeiro Paiva², Carlos Eduardo Paiva² ${ }^{2}$ Helena Megumi Sonobe ${ }^{1}$, María Paz García-Caro ${ }^{3}$, Francisco Cruz-Quintana ${ }^{3}$

Objective: to compare the health-related quality of life of cancer patients under chemotherapy treatment in Brazil and Spain. Methods: a cross-sectional study, whose data collection took place at the Hospital de Câncer and Hospital Universitário, with socio-demographic characterization instruments and European Organization for Research and Treatment of Cancer. Results: female, white, marital status, grade school students, catholic religion and the unskilled profession predominated in both countries. The scores of health-related quality of life in the health global status and the functions of role performance and cognitive functions were higher in the Brazilian sample, whereas fatigue, pain, dyspnea, insomnia and diarrhea symptoms were more present in the Spanish population, with statistically significant differences. Conclusion: health-related quality of life was better among Brazilians.

Descriptors: Quality of Life; Cross-Cultural Comparison; Culture; Drug Therapy.

Objetivo: comparar a qualidade de vida relacionada à saúde de pacientes com câncer em tratamento quimioterápico no Brasil e na Espanha. Métodos: estudo transversal, cuja coleta de dados ocorreu no Hospital de Câncer e Hospital Universitário, com os instrumentos de caracterização sociodemográfica European Organization for Research and Treatment of Cancer and Quality of Life Questionnaire-C30. Resultados: nos dois países predominaram sexo feminino, cor branca, estado civil casado, escolaridade fundamental, religião católica e a profissão não qualificados. Os escores de Qualidade de vida relacionada à saúde no Estado Geral de Saúde e as funções de Desempenho de papel e cognitiva foram maiores na amostra brasileira, enquanto que os sintomas de fadiga, dor, dispneia, insônia e diarreia foram mais presentes na população espanhola, com diferenças estatisticamente significantes. Conclusão: a qualidade de vida relacionada à saúde foi melhor entre os brasileiros.

Descritores: Qualidade de Vida; Comparação Transcultural; Cultura; Tratamento Farmacológico.

\footnotetext{
${ }^{1}$ Universidade de São Paulo. Ribeirão Preto, SP, Brazil.

${ }^{2}$ Hospital de Câncer de Barretos. Barretos, SP, Brazil

${ }^{3}$ Universidade de Granada. Espanha.

Corresponding author: Namie Okino Sawada

Av. Bandeirantes 3900, Monte Alegre. CEP: 14040-902. Ribeirão Preto, SP, Brazil. E-mail: sawada@eerp.usp.br
} 


\section{Introduction}

Currently, cancer has gained prominence in health care, since it has been one of the leading causes of death in developed and developing countries. In Brazil, as in Spain, cancer has been a growing disease of public health relevance ${ }^{(1-2)}$.

According to The Organization for Economic Co-operation and Development and the European Commission, cancer has been the second leading cause of death in Spain since the first cause is due to circulatory diseases ${ }^{(2)}$. Lung cancers, breast and colorectal tumors were responsible for the largest number of years of life lost $t^{(3)}$. Brazil follows the world trend and, since the 1960s, has undergone a process of epidemiological transition, in which infectious and parasitic diseases are no longer the main cause of death, being replaced by diseases of the circulatory system and neoplasia. This increase in the incidence and mortality due to chronic-degenerative diseases has as main factor the aging of the population, resulting from the intense urbanization process and health promotion and recovery actions ${ }^{(1)}$.

Surgical treatment of cancer and other therapeutic procedures (radiotherapy and chemotherapy) have resulted in decreased mortality and morbidity; however, there is concern about the functional conjuncture and the quality of life of these people. Thus, rehabilitation of the cancer patient is a continuous process, in order to maximize the capabilities of patients within the limitations imposed by the disease and by the treatment.

Traditional medical evaluation of the results of cancer treatment considered disease free survival, tumor response to treatment, and overall survival. However, clinicians and researchers have realized that these results are not adequate to assess the impact of cancer and its treatment on patients' daily lives. To assess these aspects, quality of life measures have been growing in current research ${ }^{(4)}$.

Thus, health-related quality of life research has helped to understanding the nature and extent of functional and psychosocial problems during the course of the disease. Another important point is the evaluation of the therapeutics and the interventions that provide better assistance to these patients and, consequently, early rehabilitation.

The concept of quality of life is subjective, multidimensional and influenced by culture ${ }^{(4)}$. Studies comparing health-related quality of life in different countries are scarce. Thus, in order to investigate and compare the health-related quality of life of cancer patients undergoing chemotherapy treatment in Brazil and Spain, the researchers/authors were awarded a scholarship by the Carolina Foundation of Spain. Therefore, the research aimed at comparing the quality of life related to the health of patients with cancer in chemotherapy treatment in Brazil and Spain.

\section{Methods}

A cross-sectional study, whose data were collected in Brazil, at Hospital de Câncer, and in Spain, Hospital Universitário, from October 2013 to January 2014.

Patients older than 18 years who underwent chemotherapy treatment and were halo-psychically oriented, with cognitive conditions preserved to respond to items of the instrument, were evaluated by simple questions such as date of birth, day of the week, address, and others. Patients with a Karnofsky Performance Scale score below 60, patients with metastasis and with chemotherapy and palliative treatment were excluded, and those who were not in preserved cognitive conditions to respond to the instrument.

In order to calculate the sample size, the average and standard deviation of the global health and social domain scores were used for the cases of Brazil and Spain mentioned in previous studies. Thus, the sample size was 154 patients for each country. The sample consisted of 159 patients from the Hospital de Câncer de Barretos (Brazil) and 154 patients from the Hospital Oncológico de Granada (Spain).

For socio-demographic and clinical data, the 
instrument was used with personal data such as origin, gender, age, skin color, marital status, current marital status, number of children; social data such as educational level, professional activity, employment status, retirement, religion and housing; source of income, monthly income, people who depend on monthly income, private health plan, physical activity and leisure and relationship with family. Clinical data include location of the primary cancer, time of diagnosis, extent of disease, treatment received, associated diseases, signs and symptoms, and patient perception of overall health status.

In order to collect data on health-related quality of life, the European Organization for Research and Treatment of Cancer (EORTC QLQ-C30) instrument was validated in Brazil, in patients with lung cancer ${ }^{(5)}$, and in the Spain, in patients with prostate cancer ${ }^{(6)}$. In all studies, the instrument demonstrated satisfactory psychometric properties. The European Organization for Cancer Research and Treatment is a quality of life instrument for cancer patients with 30 questions that comprise five functional scales: physical, cognitive, emotional and social functions and role performance; Three scales of symptoms: fatigue, pain and nausea and vomiting, a global health/quality of life scale and five other items assessing symptoms commonly reported by cancer patients: dyspnea, loss of appetite, insomnia, constipation and diarrhea, and an item evaluating the financial impact of treatment and illness. In order to analyze the results of the EORTC QLQ-C30 instrument, it was considered that the general health, quality of life, physical function, role performance, emotional function, cognitive function and social function These conditions, whereas in the scales of symptoms and financial difficulties the closer to 100 means the greater presence of these symptoms and difficulties.

The analysis of the data was carried out in the light of the model proposed by Kimlin Tam Ashing-Giwa that considers two levels: the macro and the micro that are related to the life experience of the individual. The macro level (systemic context) is composed of four dimensions: socio ecological, cultural, demographic and health system. The micro level (individual context) considers the experience of living with cancer in four dimensions: general health and comorbidities, cancer-specific medical factors and effective health ${ }^{(7)}$.

The data were analyzed in a quantitative manner, submitted to statistical treatments by the Statistical Package for Social Science. A descriptive analysis was performed for socio-demographic, clinical and therapeutic data. The Mann Whiteney test was used to compare the domains of the instrument health-related quality of life with socio-demographic, clinical and therapeutic data between the two samples.

The study complied with the formal requirements contained in national and international standards for research involving human subjects.

\section{Results}

The results of socio-demographic characterization in Brazil showed that of the total of 159 patients, $98(61.6 \%)$ were female; average age of 51.6 years; white skin color 92 (57.5\%), yellow 2 (1.3\%), brown 54 (33.8\%) and black 11 (6.9\%); married 89 (55.6\%), consensual union 18 (11.3\%), widowed 6 (3.8\%), separated 12 (7.5\%) and divorced 12 (7.5\%); (51.3\%), secondary education 51 (31.9\%) and higher education 18 (11.3\%), with no relation to the educational level. Category 1 - Public service 3 (2.0\%), category 2 - specialists in the intellectual and scientific professions 8 (5.0\%), category 3 - Level technicians and professionals, category 6 - farmers and agricultural workers $22(14.0 \%)$, category $9(8.0 \%)$, category 4 administrative and similar staff 15 (9.0\%), category 5 - service and sales staff 29 (18.0\% - unskilled workers 56 (35.0\%), 3 did not respond to the profession. As to religion, 108 (67.5\%) were catholic, 40 (25.0\%) evangelicals, $3(1.8 \%)$ spiritualists and $3(1.8 \%)$ did not respond.

The total sample from Spain was 154 patients with the following characteristics: 117 (7.6\%) female, average age 52 years; white skin color 141 (91.6\%), 
yellow 3 (1.9\%), brown 7 (5.4\%); marital status: single married $16(10.4 \%)$ married $110(71.4 \%)$, consensual union 12 (7.8\%), widowed 4 (2.6\%), separated 8 (5.2\%) and divorced 12 (7.8\%); concerning schooling $5(3.2 \%)$, with no schooling, grade school 50(32.5\%) high school $39(25.3 \%)$ and university education 57 $(37.0 \%)$. In relation to the profession, category 2 there were 7 (5.0\%), $9(8.0 \%)$ in category $3,15(10.0 \%)$ in category 4, $8(5.0 \%)$ in category $5,3(2.0 \%)$, in category $6,3(2.0 \%)$ in category 7 , and $16(10.0 \%)$ in category 9 , it is worth noting that $93(60.0 \%)$ did not respond to the item profession; regarding religion, 137 (89.0\%) were catholic, 11 (7.1\%) evangelicals, 6 (3.9\%) spiritualists.

Table 1 - Comparison of the averages of the EORTC QLQ-C30 scores of Brazil and Spain

\begin{tabular}{|c|c|c|c|c|c|}
\hline \multirow[b]{2}{*}{ Domains } & \multicolumn{2}{|c|}{ Brazil ( $n=159)$} & \multicolumn{2}{|c|}{ Spain $(n=154)$} & \multirow[b]{2}{*}{$\begin{array}{c}\mathbf{p} \\
\text { value }\end{array}$} \\
\hline & Average & $\begin{array}{l}\text { Standard } \\
\text { deviation }\end{array}$ & Average & $\begin{array}{l}\text { Standard } \\
\text { deviation }\end{array}$ & \\
\hline Globol status of health & 79.04 & 19.0 & 58.62 & 22.71 & $<0.001$ \\
\hline Physical function & 78.20 & 21.19 & 77.80 & 19.92 & 0.610 \\
\hline Role performance & 86.16 & 25.51 & 67.86 & 27.62 & $<0.001$ \\
\hline Emotional function & 81.55 & 26.82 & 82.24 & 19.85 & 0.216 \\
\hline Congnitive function & 85.53 & 26.12 & 69.17 & 28.70 & $<0.001$ \\
\hline Social function & 70.91 & 30.93 & 71.97 & 25.60 & 0.629 \\
\hline Fatigue & 26.28 & 27.05 & 39.71 & 26.37 & $<0.001$ \\
\hline Nausea & 12.79 & 21.39 & 14.19 & 20.92 & 0.245 \\
\hline Pain & 25.26 & 33.53 & 29.54 & 27.18 & $<0.008$ \\
\hline Dyspnea & 8.18 & 18.26 & 17.08 & 27.01 & $<0.002$ \\
\hline Insomnia & 27.04 & 37.15 & 33.08 & 32.01 & $<0.022$ \\
\hline Loss of appetite & 21.38 & 34.43 & 23.77 & 27.14 & 0.065 \\
\hline Constipation & 24.53 & 36.05 & 28.56 & 31.32 & 0.065 \\
\hline Diarrhea & 7.81 & 19.96 & 13.39 & 23.02 & $<0.007$ \\
\hline Financial difficulty & 22.22 & 33.68 & 24.65 & 32.74 & 0.346 \\
\hline
\end{tabular}

Table 1 shows the comparison of the assessment of health-related quality of life of the two countries, revealing that the health global status and role and cognitive performance functions were higher in the Brazilian population. The symptoms of fatigue, pain, dyspnea, insomnia and diarrhea were more present in the Spanish population, with a statistically significant difference, evidencing that the quality of life related to the health of the Brazilians was better than the Spanish sample.

The results of the comparison between the health-related quality of life scores of the two independent samples associated with socio-demographic and clinical data showed statistically significant differences in gender, schooling level, physical activity, tumor extent, marital status, time of diagnosis and area of housing.

\section{Discussion}

The method used has generated some limitations such as the heterogeneity of cancer types and chemotherapy protocols, as well as few researches that evaluate health-related quality of life among different countries, using the same theoretical framework adopted, which made comparison and discussion difficult.

The analysis of the macro level of the theoretical framework that involves the social, cultural, and demographic context and health system will be discussed below.

The socio-demographic data of the two countries show similarities in the aspects of gender, age, marital status, educational level, religion and profession. According to the National Statistics Institute, the total Spanish population for the year 2008 was approximately 46.2 million inhabitants, of which 22.8 million (49.5\%) were male and 23.3 million (50.5\%) women ${ }^{(8)}$. The demographic statistics of Spain point out that the majority of the population attended basic and secondary education and in the age group over 40 , most of them married. With regard to employment, the data for 2013 indicated that $4.4 \%$ were employed in agriculture, forestry and fisheries services, $24.7 \%$ in industry, construction and energy and 74.9 in services ${ }^{(9)}$. 
The Catholic religion prevailed. It should be noted that in the late 1970s, nine out of ten Spaniards declared themselves Catholic and fifteen years later, eight out of ten Spaniards continued to consider themselves Catholic ${ }^{(10)}$.

Given that it is worth noting that $60.4 \%$ of the Spanish sample did not respond to the profession and retirement, it can be inferred that this is due to the high level of unemployment that the country has faced. According to statistics, the unemployment rate in Spain is $24.4 \%{ }^{(9)}$. Thus, it is considered that the socio-demographic data found in this study corroborate the statistics of Spain.

Similarly in Brazil, in 2011, in the group of people aged 60 and over, the proportion reached 79.5 men for every 100 women in the same age group, since the mortality rate among men is higher. The census in 2013 showed that in the Brazilian population, the majority was married, in the age group over 40 years, basic educational level and catholic religion. Regarding employment in Brazil, the data show that there are still a large percentage of informal workers, in $2011,42.8 \%$ of men and $35.1 \%$ of women worked without a formal contract ${ }^{(11)}$.

Data indicate that economically disadvantaged populations are more likely to become ill and that economic, social and environmental conditions influence the person's health-disease process, contributing to the establishment and development of chronic diseases, such as cancer ${ }^{(1)}$. Thus it is evident that the socioeconomic development of a country has a direct influence on the health of the population.

Since 2003, Spain's health system has been decentralized after 20 years of reforms, resulting in 17 autonomous communities that are responsible for providing and financing health care in their territories, the model of specialized care varies according to the autonomous communities and the main problems are of records and diagnoses, delay in treatment and waiting time. Despite these problems, users have evaluated the services as satisfactory ${ }^{(12)}$.

In Brazil, statistics show that the average family size is 2.6 persons per family, $85.0 \%$ live in the urban area and in the region of the State of São Paulo, where $96.8 \%$ of the population is concentrated in the urban area $^{(11)}$. The health system in Brazil is composed of two subsystems: the public and the private. In Brazil, the public system is formed by the Unified Health System, of universal character and free access of public financing; and the private subsystem is composed of complementary health, composed of individual or collective volunteer health plans and insurance, financed by employers or by the families and direct disbursement, access to the health service is made through payment in the act of providing services ${ }^{(13)}$.

The theoretical model of Ashing Giwa emphasizes that the low socioeconomic situation presents difficulties for the individual and the family with regard to access to the specialized services of health, transportation and unemployment and the condition of life (housing, day to day stressors, functional role, among others) becomes an obstacle to adequate resources for health maintenance, directly affecting health-related quality of life $\mathrm{e}^{(7)}$.

When analyzing the living conditions in the two countries, there are similarities in housing conditions, monthly income from one to three minimum wages and the type of access to the health service. Regarding aspects of relationship with health professionals and the attendance of needs, it was found that the majority in Brazil considered these items to be optimal and inferred that it is due to the care provided by Hospital do Brasil. This hospital, in 2009, received the certificate of fully accredited hospital by the Qualisa Institute of Management that evaluated as one of the strengths, the projects of humanization and personalization of patient care and its mission is to provide qualified and humanized cancer care.

The following will discuss aspects of the micro level (individual context) that considers the experience of living with cancer such as general health, medical factors and effective health.

When analyzing the clinical data, similarities were also observed in both countries, regarding the 
location of the tumor, the three most frequent types of cancer were breast cancer, gynecological and colorectal cancer; most had diagnostic time of less than six months and were submitted to biopsy and organ removal, were not subjected to radiotherapy and only the extent of the disease differed in the countries, predominating the local extension in the Brazilian sample and the regional in the Spanish sample. The results corroborate estimates of the incidence and prevalence of cancer in Brazil and Spain in women, with breast cancer being the most frequent, followed by gynecological and colorectal cancer ${ }^{(1,3)}$.

As for the time of diagnosis, the majority was less than six months in both countries and the extent of the disease was worse in the Spanish sample, with the regional majority; with respect to the surgical procedure, most were biopsies, followed by organ removal in both countries. The radiotherapy treatment was not performed by the majority and all were performing the chemotherapy treatment in the two samples. The type of treatment depends on the location of the tumor and the staging; however the most common treatments are surgery, radiotherapy and chemotherapy.

The results of this research differ from the one that carried out an analysis of the health-related quality of life, using the European Organization for Research and Treatment of Cancer, in several countries of Europe, Asia and Latin America. South of Europe (France, Spain, Italy, Switzerland and Portugal) of 64.9 and in Latin America (Brazil and Argentina) of 56.8. This difference is explained considering cultural aspects, that is, distinct cultural groups value the aspects of health-related quality of life differently ${ }^{(14)}$.

It agrees with this elucidation that meets the referential adopted by this study, which considers culture as the major determinant of quality of life. This model considers that general health, cancer-specific clinical factors, and health control are individual factors, unlike the macro dimensions of the model that have a more global and less direct impact on health-related quality of life outcomes. Factors seem to exert significant and direct influences on the patient's life. Thus, the presence of symptoms also influences health-related quality of life, as observed in the Spanish sample, which had greater presence of fatigue, pain, dyspnea, insomnia and diarrhea, proving the health-related quality of life model as multidimensional construct, whose presence of symptoms compromises it.

The result was statistically significant for males who had a higher average in the Health Global Status, Role Performance and Cognitive Function, than women in the Brazilian and Spanish sample. The symptoms of fatigue, pain, dyspnea and diarrhea were more present in women in both countries. EORTC QLQ-C30 instrument from six European countries also found better overall health, better functioning and fewer symptoms, especially fatigue and pain, in men than in women $^{(15)}$.

In the Spanish and Brazilian samples, the averages of the Health Global Status, Role Performance and Cognitive Function were lower and statistically significant in the lower levels of education, and the symptoms were also more present in these categories. The data corroborate with research on the perception of the health status of elderly adults according to socio-demographic differences and regions that demonstrated a high proportion of respondents with less schooling in the region of Andalusia, showing a more negative perception of health status ${ }^{(16)}$.

The theoretical framework adopted considers culture as the major determinant of quality of life, so the different cultural groups value different aspects of health-related quality of life, that is, the results may simply be reflecting these differences, it is understood that people of different cultures interpret and express what they mean by quality of life in general and general health, since health-related quality of life is a subjective construct ${ }^{(7)}$.

Culture is fundamental to human life, it prescribes the ways of life of a group of people to ensure survival and well-being, and it determines the beliefs and values that give meaning and purpose to life ${ }^{(17)}$. Every 
culture determines the universal needs, such as security, the sense of integrity and meaning or purpose in life, and the sense of belonging as an integral member of the social network. Thus, each culture has a set of beliefs, values and practices that determine the identity of the group and are generally not isomorphic with other cultural groups. Often, there are similarities between cultural groups along with different ranks, such as the influence and variations of Buddhism on the ways of life in Eastern countries, or the variations of Christianity and its effects on cultures in the West and East.

Regarding physical activity, there was a statistically significant difference in both countries, and the group that performed physical activity obtained a higher score in the health global status, role performance and fewer symptoms of pain, dyspnea, insomnia and diarrhea in the Brazilian sample, corroborating other studies that demonstrated a positive association between physical activity and quality of life $\mathrm{e}^{(18-19)}$.

Effective health is another contextual dimension of the individual level of the model adopted, so that the patient's effectiveness or ability to develop behaviors and good health practices for health maintenance and promotion are interrelated to health-related quality of life outcomes. Therefore, the development of personal attitudes and abilities, which promote healthy health habits, at all stages of life, will reflect health promotion actions and, consequently, better quality of life. In this way, this dimension is also influenced by the cultural dimension of the macro level, becoming important determinants for health practice and health-related quality of life of cancer patients.

It is understood that this research advanced knowledge in the area of health-related quality of life, with a cultural approach, and may subsidize other research studies. Thus, it is emphasized that adopting a theoretical framework is important to provide greater understanding of results and generalization of research data.

\section{Conclusion}

The health-related quality of life was better, in the domains of general health and the functions of role and cognitive performance, in the Brazilian population. The symptoms of fatigue, pain, dyspnea, insomnia and diarrhea were more present in the Spanish population, with a statistically significant difference, evidencing that the health-related quality of life of the Brazilians was better than the Spanish sample.

\section{Collaborations}

Sawada NO contributed for the conception of the project, data interpretatio and approval of the final version to be published. Paiva BSR, Paiva CE, Sonobe HM, García-Caro MP and Cruz-Quintana F contributed for the writing and relevant critical revision of the intelectual contents.

\section{References}

1. Barbosa IR, Souza DLB, Bernal MM, Costa ICC. Cancer mortality in Brazil temporal trends and predictors for the year 2030. Medicine [Internet]. 2015 [cited 2017 Jun 05]; 94(16):e746. Available from: https://insights.ovid.com/ pubmed?pmid $=25906105$

2. Organization of Economic Co-operation and Development. Health at a glance: Europe 2016 State of health in the EU cycle, OECD Publishing, Paris [Internet]. 2016 [cited 2016 Nov 30]. Avaiable from: htpp://www.oecd.org/rights

3. Ferlay J, Steliarova-Foucher E, Lortet-Tieulent J, Rosso S, Coebergh JWW, Comber H, et al. Cancer incidence and mortality patterns in Europe: estimatives for 40 countries in 2012. Eur J Cancer. 2013; 49(6):1374-403.

4. Kings CR,Hinds PS. Quality of life from nursing and patients perspective, Washington DC, third edition, United Kingdom. Sudbury, Mass: Jones Barlett Learning; 2012. 
5. Brabo EP, Paschoal MEM, Biasoli I, Nogueira FT, Gomes MCB, Gomes IP, et al. Brazilian version on the QLQC 13 lung cancer: preliminary reability and validity report. Qual Life Res. 2006; 15(9):151924.

6. Urdaniz JIA, Lturre EV, Vega FA, Domínguez MAD, Milagro NL, Burgaleta AM, et al. The EORTC quality of life questionnaire QLQ C30 (version 3.0) validation study for spanish prostate cancer patients. Arch Esp Urol. 2008; 61(8):949-54.

7. Ashing-Giwa KT. The contextual modelo of HRQoL: a paradigm for expanding the HRQoL framework. Qual Life Res. 2005; 14(2):297-30.

8. Instituto Nacional de Estadística. Anuário Estadístico de España [Internet]. 2009 [cited 2016 nov 30]. Avaiable from: htpp:// http://www.ine. es/inebmenu/indice.htm\#30ml

9. Instituto Nacional de Estadistica. Anuário Estadistico de España [Internet]. 2014 [cited 2016 nov 30]. Avaiable from: htpp://www.ine.es/prodyser/ pubweb/anuario14/anu14_08merca.pdf.

10. Ferreira AM, Almeida JM. Religião e cidadania protagonistas, motivações e dinâmicas sociais no contexto ibérico. Lisboa: Fundação para Ciência e Tecnologia; 2011.

11. Instituto Brasileiro de Geografia e Estatística. Síntese de indicadores de vida da população brasileira [Internet]. 2014 [citado 2016 nov 30]. Disponível em: htpp:// http://www.ibge.gov.br/ home/mapa_site/mapa_site.php\#populacao

12. Astier-Peña MP. Atenção primária à saúde na Espanha. Rev Bras Fam Comunidade. 2014; 9(33):391-4.
13. Paim J, Travassos C, Almeida C, Bahia L, Macinkop J. 0 sistema de saúde brasileiro: história avanços e desafios [Internet]. 2011 [citado 2016 nov 30]. Disponível em: http://actbr.org.br/uploads/ conteudo/925_brazil1.pdf

14. Scott NW, Fayers PM, Aaronson NK, Bottomley A, Graeff A. The relationship between overall quality of life and its subdimensions was influenced by culture: analysis of an international database. J Clin Epidemiol. 2008; 61(8):788-95.

15. Hinz A, Singer S, Brähler E. European reference values for the quality of life questionnaire EORTC QLQ-C30: Results of a German investigation and a summarizing analysis of six European general population normative studies. Acta Oncol. 2014; 53(7):958-65.

16. Fernandez-Martinez B, Prieto-Flores ME, Forjaz MJ, Fernandéz-Mayoralas G, Rojo-Perez F, Martinez-Martin P. Self-perceived health status in older adults: regional and sociodemographic inequalities in Spain. Rev Saúde Pública. 2012; 46(2):310-9.

17. Kagawa-Singer M. Applyig the concept of culture to reduce health disparities through health behavior research. Prevent Med. 2012; 55(5):356-61.

18. Ruiz-Casado A, Verdugo AS, Solano MJ, Aldazabal IP, Fiuza-Luces C, Alejo LB, et al. Objectively assessed physical activity levels in Spanish cancer survivors. Oncol Nurs Forum. 2014; 41(1):1-9.

19. Pucci GCMF, Rech CR, Fermino RC, Reis RS. Association between physical activity and quality of life in adults. Rev Saúde Pública. 2012; 46(1):166-79. 